\title{
Uptake and early removals of Implanon NXT in South Africa: Perceptions and attitudes of healthcare workers
}

\author{
O A Adeagbo, ${ }^{1} \mathrm{MA}, \mathrm{PhD} ; \mathbf{S}$ Mullick, ${ }^{1} \mathrm{MB} \mathrm{ChB}, \mathrm{MSc}, \mathrm{MPH}, \mathrm{PhD} ;$ D Pillay, ${ }^{1} \mathrm{MPH} ; \mathbf{M}$ F Chersich, ${ }^{1} \mathrm{MB} \mathrm{BCh}, \mathrm{PhD}$ \\ C Morroni ${ }^{1,2,3,4}$ MB ChB, DFSRH, DTM\&H, MPH, MSc, PhD; N Naidoo, ${ }^{1}$ MPH; M Pleaner, ${ }^{1}$ MEd; \\ H Rees, ${ }^{1}$ MB BChir, MA (Cantab), MRCGP, DCH, DRCOG \\ ${ }^{1}$ Wits Reproductive Health and HIV Institute, Faculty of Health Sciences, University of the Witwatersrand, Johannesburg, South Africa \\ ${ }^{2}$ Women's Health Research Unit, School of Public Health and Family Medicine, Faculty of Health Sciences, University of Cape Town, South Africa \\ ${ }^{3} E G A$ Institute for Women's Health and Institute for Global Health, University College London, UK \\ ${ }^{4}$ The Botswana-UPenn Partnership, Gaborone, Botswana
}

Corresponding author: O A Adeagbo (oadeagbo@wrhi.ac.za)

Background. The South African (SA) government introduced Implanon NXT, a long-acting subdermal contraceptive implant, in 2014 to expand contraceptive choice. Following an initial high uptake, its use declined considerably amid reports of early removals and frequent side-effects. We examine providers' perceptions of training and attitudes towards Implanon NXT, as well as their views on the causes of early removals and the impact on the implant service.

Objective. To assess healthcare providers' perceptions and attitudes towards implant services in SA.

Methods. In-depth interviews were conducted with eight nurses providing implant services in public facilities in Gauteng and North West Province. Emerging themes were identified, manually coded and thematically analysed following an interpretivism approach.

Results. Nurses lacked confidence in providing implant services effectively, particularly removals, which they ascribed to the brief, cascade-type training received. Nurses generally held negative views towards the method. They also reported that side-effects are the most common reason for early removals - particularly irregular bleeding - and that men often do not support their partners who use the method. Lastly, it was found that providers require guidance on counselling regarding the method and standardised guidelines on the management of side-effects.

Conclusion. Retraining and support of providers are needed to address competency gaps and negative attitudes towards the method. Assessment of providers' readiness to perform removal procedures is also important. Finally, effective plans are necessary to improve implant continuation rates, especially among women whose partners are unsupportive.

S Afr Med J 2017;107(10):822-826. DOI:10.7196/SAMJ.2017.v107i10.12821

The Sustainable Development Goals (SDGs), commissioned in 2015, include universal access to sexual and reproductive health, and make direct references to addressing the unmet contraceptive needs of women. ${ }^{[1]}$ Similarly, Family Planning 2020 (FP2020) aims to make modern contraceptive methods accessible to an additional 120 million women by $2020 .{ }^{[2]}$ These initiatives are particularly pressing in subSaharan Africa, where most women of reproductive age still have unmet contraceptive needs, despite considerable increases in contraception coverage over the past two decades. ${ }^{[3,4]}$

In South Africa (SA), the 2016 Demographic and Health Survey (DHS) estimated that unmet needs for contraception were as high as $39 \%$ among married and sexually active unmarried women. Cognisant of these gaps in services, the SA government has committed to achieving the SDGs around family planning and the FP2020 goals, which align with the country's laws and policies that support sexual and reproductive health and rights. ${ }^{[3]}$ The 2001 National Contraceptive Policy Guidelines (updated in 2012), the National Health Act as well as the National Adolescent Sexual and Reproductive Health and Rights Framework Strategy (2014 - 2019) recognise the challenges and health needs of women and adolescents, particularly family planning needs. ${ }^{[3,5-8]}$

Consistent with the 2012 Contraception Policy objectives, the National Department of Health (DoH) introduced Implanon NXT in 2014 to increase the range of contraceptive options for women, particularly long-acting methods. ${ }^{[9,10]}$ Implanon NXT is a single-rod subdermal implant containing $68 \mathrm{mg}$ of the progestin etonogestrel and offers 3 years of highly effective pregnancy protection $(<1$ pregnancy per 100 women-years). ${ }^{[5]}$ Before implant roll-out, preparations such as healthcare provider training, programmatic guidelines and manual development were put in place, and $>6000$ healthcare providers trained across the country, mostly using a cascade training approach - training provided by healthcare workers who have attended a training. ${ }^{[3]}$

Based on the DHS, almost $4 \%$ of women of reproductive age were using the implant by 2016, with injectables remaining the most common method, accounting for $25 \%$ of contraceptive coverage. ${ }^{[11]}$ Concerns, however, have grown about a sharp decline in implant method uptake and rise in the number of women returning for early removal of the implant, mostly because of intolerable side-effects. ${ }^{[3]}$ Implant side-effects received negative attention from the general populace (including healthcare workers and the media) in SA, which has brought into question the appropriateness and sustainability of the method in the country. Side-effects, especially bleeding, are also the main cause of early removal in other areas, although studies across a range of settings, including sub-Saharan Africa, indicate that between $80 \%$ and $85 \%$ of users continue the method 1 year after insertion, ${ }^{[12,13]}$ including women $<25$ years of age. ${ }^{[14]}$ A minority of studies reported continuation rates of $70 \%$; again, mostly ascribed to changes in bleeding patterns. ${ }^{[15-17]}$

Clearly, family planning providers are critical to the success or failure of contraceptive programmes, and play a crucial role in shaping how women perceive a contraceptive method. In Mali, for example, providers in community health centres served as positive 
agents of change, increasing access and quality of family planning services, particularly for the implant. ${ }^{[18]}$ We, therefore, conducted a qualitative study of providers' attitudes towards the implant and their perspectives on the factors that underlie early removals, as well as how these have influenced uptake of the method.

\section{Methods}

This article draws on data collected in a mixed-methods evaluation, which aimed to assess the effectiveness of Implanon NXT services in SA. The evaluation included primary healthcare (PHC) clinics, sampled from the City of Johannesburg (CoJ), Gauteng, (6 clinics) and Dr Kenneth Kaunda District (DKKD), North West Province (6 clinics). Participants consisted of family planning service providers (also referred to as nurses), who were purposively selected on the basis of having been directly involved in the provision of implant services. Of 13 professional nurses contacted across the 12 participating facilities, 8 agreed to be interviewed ( 3 were no longer working at the facility and 2 declined to participate). Five nurses in CoJ, who were drawn from four facilities, participated, and 3 nurses in DKKD, each representing one facility. Data were collected through face-toface in-depth interviews in May - November 2016. All participants were female, and their ages ranged between 29 and 60 years.

The interview guide was piloted and revised before data collection commenced. Interview questions included enquiry about the implant and general family planning training the nurses had received, their perception of levels of removal and reasons for removal, their personal attitudes towards the implant, and perceptions of women's experiences with regard to side-effects and their partners' reaction to these. Interviews took place in the facility, at a location chosen by the participant. These were conducted in English by trained female field workers, although in a few instances interviewers translated some words from English to the local languages of participants for ease of comprehension. Conversations lasted $1-2$ hours and were digitally recorded. Telephonic follow-up interviews were done with some of the providers (two each in both DKKD and CoJ) to further clarify aspects of the interviews. Interview transcripts were reviewed by the lead researcher (OAA) and another investigator (DP). Emerging themes were identified, categorised manually and analysed thematically following interpretive ideology ${ }^{[19]}$ The study was approved by the Human Research Committee of the University of the Witwatersrand, Johannesburg (ref. no. M151147) and permission for the study was granted by the DoH.

\section{Key findings and discussion}

This section presents the main themes emerging from the data. It begins with a discussion about the perceptions of providers towards the training they received, and then examines providers' experiences with dealing with implant side-effects, counselling and management, and removal. The final sections explore providers' attitudes towards the implant, as well as their perceptions of men's involvement and influence in women's decisions to begin and continue or discontinue the method.

\section{'We were only trained for 2 days': Impact of insufficient training on service delivery}

This theme examines the training that healthcare providers received on insertion and removal of the implant, as well as on counselling about the method and providing long-term support for women using the implant. The impact of gaps in training is also discussed and potential actions that might be taken by the $\mathrm{DoH}$ to address these. The following excerpts show individual interviewees' perceptions of the training they received:
'... We were only trained for 2 days ... I feel like the training was not sufficient ... I think I need intense trainings in order for me to deliver the service effectively.' (Professional nurse H, DKKD)

'We had some trainings and we were shown how to insert and remove the implant and each clinic was expected to do that ... It was like a once-off thing ... ? (Professional nurse E, CoJ)

'... I was trained by another professional nurse, I would really not call it a proper training honestly ... I think I need to start afresh when it comes to the implant and receive training for months .... ? (Professional nurse A, DKKD)

'My colleagues went for the theory part and I went for the practical training on insertion ... I don't think I have had sufficient training to do this ... ? (Professional nurse $\mathrm{F}, \mathrm{CoJ}$ )

Providers' perceptions of having received inadequate training on Implanon NXT provision came out strongly across the interviews. In particular, they indicated that the training was too brief and covered only some components of the service, and that little or no refresher training and long-term support have been made available. Providers felt that the training was insufficient, given what they perceived to be the complexities of the method. According to nurse F, there were also considerable gaps in the training: '... If I remember correctly, I was only trained on the insertion ... ? Importantly, nurse A believed that having being trained by a colleague (the cascade training approach), who had been to only one training session, was insufficient to equip her to provide the method.

From the nurses' perspectives, inadequate training had directly affected the quality of the services they provided. This especially related to inadequate understanding of the method, limited training on how to counsel women about the method, as well as deficiencies in practical skills for implant removal. Perceived deficiencies in their knowledge and how to counsel, as well as their practical skills for implant provision, meant that nurses lacked confidence in their ability to provide quality services; one (nurse H) saying: 'When clients came, I wasn't sure of what I was doing', and similarly, another (nurse F) simply said: '... I don't know enough ... . Despite a strong sense of deficiencies in their training, nurses continued to provide the service, with one (nurse A) noting: '... I try to counsel the client with the little knowledge that I have ... ? Nevertheless, gaps in knowledge and skills, and the providers' own doubts in their competencies, may undermine the quality of services provided, as noted in the section below on implant removals. Consistent with this, several studies on implant services in a range of settings have shown that providers' level of knowledge, especially around counselling, is a key determinant of the uptake of the implant and subsequent continuation..$^{[9,15,18,20]}$ Of note, a study across several sub-Saharan African countries showed the benefits of competency-based training on the implant, sideeffect management, and regular mandatory refresher courses and mentorship. ${ }^{[9]}$ These efforts boosted the confidence of providers to remove implants; at follow-up, none of those trained had refused to do removals, an issue which had previously hampered the programme. ${ }^{[9]}$

All the nurses expressed enthusiasm about the prospect of attending further training by qualified personnel. Opportunities for practical experience, where several insertions and removals are done under supervision, and for continued mentoring, appear to be particularly important, with nurse E saying: 'It just needs some practice. The more you insert or remove, the more you'd be skilful ... ? Overall, more intensive training, grounded in effective training methodologies, could augment individual provider's skills, empowering them to become increasingly confident and competent. Practically, this might entail: ( $i$ ) reassessing the training curriculum, 
and evaluating and revising the training provided, with input from providers who previously completed training; (ii) providing refresher training (both theory and practical) on counselling, side-effect management, insertion and removal; (iii) using master trainers, rather than cascade training; and (iv) offering ongoing in-service mentorship and competency sign-off.

\section{'My concern is the side-effects': Providers' perceptions of how side-effects impact on uptake and removal of Implanon NXT}

The views of the nurses on the impact of side-effects on uptake and early removals of Implanon NXT are articulated below:

'... More women would use it, but my concern is the side-effects ... The last time I inserted Implanon was last year ... The main reason is the side-effects and more medical research has to be done so that we can introduce it again to the public ... ? (Professional nurse A, DKKD)

'... The last time we inserted one [Implanon NXT] was in early 2015, and three months after we started doing removals. The news of side-effects is travelling fast because people talk ... I have been threatened many times by clients because they want to get it removed immediately and we have had cases where clients are removing it themselves because of side-effects, especially bleeding ... ? (Professional nurse B, CoJ)

‘... [Implanon NXT] was recently introduced and in no time many women complained about it and would remove it immediately ... Yes! Side-effects, such as excessive bleeding, cramps, headaches and dry mouth, are the reasons why clients are removing the implant ... ? (Professional nurse G, DKK)

'... It [Implanon NXT] didn't actually thrive well because of the adverse symptoms ... ja [yes]! They don't like the bleeding part ... Initially we were told to give Ovral as we normally do when they bleed with Depo and others, but at the later stage we were told to give Ovral and Triphasil ... The medications do not usually stop the bleeding; hence, you see clients coming here to fight for removals ... People often come here to remove the implant and nobody wants to insert it because of the side-effects ... ? (Professional nurse E, CoJ)

From the abovementioned quotes, it is clear that adequate preparation of women for potential side-effects and management thereof, including being able to confidently counsel women on which sideeffects are likely to be related to the implant or are coincidental, poses a considerable challenge to Implanon NXT provision and use in SA, with similar themes emerging from all nurses interviewed. As reported by providers, the main factor underlying removal of implants was intolerable side-effects, especially irregular bleeding.

Changes in bleeding patterns, with almost all users experiencing some change and most experiencing light but unpredictable bleeding $(\sim 3 / 5)$, but some experiencing prolonged and/or heavy bleeding $(\sim 1 / 5)$, is a well-documented and expected side-effect of the implant. Thorough precounselling about this and discussion of the potential implications for users are essential to ensure that the implant is an appropriate method for the women who choose it. Even so, many users will need support and may choose to discontinue the method. Despite the changes in bleeding patterns and other side-effects, many studies have shown that, overall, Implanon NXT is highly acceptable, and most users view the method positively. ${ }^{[13,15,21,22]}$

Providers highlighted their need for clear guidelines on how to deal with side-effects. A variety of medications had been given, similar to those prescribed to clients who have irregular bleeding with injectable and other contraceptive methods, but without a standardised and evidence-based approach. Available evidence and guidelines elsewhere on side-effect management could be used to devise a standardised approach for SA.

In summary, it is clear that providers in SA require additional tools on side-effect counselling and management to assist potential users in making informed contraceptive decisions, and supporting ongoing use of the implant when chosen. Extensive counselling and followup care by providers can raise continuation rates. ${ }^{[9]}$ Clearly, women require detailed and evidenced-based counselling that encompasses the likely side-effects and other features of the method, their motivations and expectations of the method, as well as the meanings that they attribute to menstrual bleeding, and implications for their bleeding patterns. Equally, however, ongoing counselling and support for those experiencing side-effects are critical for optimising implant continuation rates.

\section{'We don't know what we are damaging inside': Providers' experience of Implanon NXT removal}

The preceding themes grappled with the nurses' experiences of training and gaps in competence and confidence, as well as their perspectives on reasons for early removal. This theme explores the experiences of providers in managing implant removals. The following quotes shed light on the challenges encountered in this regard:

... Removals take forever [up to 2 hours] ... it's hard to remove those things [Implanon] ... You worry about what you are damaging inside, because you are cutting with a blade and making a hole to get to the position of the implant in the flesh ... ? (Professional nurse $\mathrm{B}, \mathrm{CoJ}$ )

‘... Insertion was quite easy, but removal was a problem in almost all the clinics because people are coming here from other clinics to remove. I don't know why the nurses are sending those who want to remove away ... Maybe they are scared, but it's time consuming though ... We sometimes struggle when removing the implant .... (Professional nurse E, CoJ)

'... Sometimes the implant just disappears on the body and the doctor had to struggle to get it ... I prefer insertion to removal because removal takes a lot of time ... ? (Professional nurse $\mathrm{C}, \mathrm{CoJ})$

The above quotes reveal the significant concerns among providers about Implanon NXT removals, especially around the potential complications, the time required to perform the procedure and the consequent impact on their other services and duties. Nurses uniformly indicated that they lack confidence with regard to implant removal skills and do not feel sufficiently competent with the procedure. Some explained that clients can become aggressive if the removal process is prolonged. Providers clearly linked the challenges they are facing with implant removals to having received inadequate training. For some, this meant that they did not engage in implant removals, while others took the initiative to perform removals despite this. Both approaches - unwillingness to remove the implant when a client wanted to discontinue or feeling incompetent to do so - were considered to have negative implications for provider-client relationships and women's trust in family planning services as a whole. One respondent also raised concerns about whether the surgical process of removal should be within the scope of a nurse's duties: ‘... I think doctors should be removing the implant ...? (Nurse B).

Since Implanon NXT provides 3 years of protection against pregnancy before a replacement is required, ensuring there are effective services in place for removal is becoming ever more urgent. ${ }^{[9,23]}$ To address this issue, one implant programme that operated across 15 countries chose 
to link women to specific clinics where providers had been selected and trained in removal and other aspects of follow-up care. ${ }^{[9]}$ This approach had resolved many of the previous challenges with removals. Clearly, providers' competence to perform removal procedures needs to be carefully assessed to ensure that they are able to remove the device timeously and safely, or to refer as necessary for difficult removals. Moreover, this task might extend beyond the scope of work of some nurses, so in some settings, removals may perhaps be reserved for specially trained nurses and doctors with the necessary expertise. Furthermore, adequate referral protocols are necessary, with clear criteria and pathways for difficult removals (e.g. impalpable, deep or inappropriately placed implants that may require special techniques or radiological investigation) that cannot be done by usual providers or in an outpatient clinic setting.

\section{'I wouldn't recommend it to my daughter': Providers' perceptions of Implanon NXT}

This theme engages with the perceptions and attitudes of family practice providers towards Implanon NXT, as they are at the interface of client decision-making with regard to the implant and other contraceptives and, as such, may play a crucial role in how women perceive the method. The following excerpts provide insights into the attitudes of the providers:

'... I have a duty to inform the client of all the methods and the client must choose. She must make an informed decision based on what I explained to her without hiding it ... It has not been well received ... The thing [Implanon NXT] that should be there for 3 years is being removed within a short space of time, especially during the first year of insertion ... Given the state of financial problem that our country is in, I believe it's not worth it ... It has lots of problems that it has created socially and mentally ... ? (Professional nurse E, CoJ)

'... To tell you the truth, lately, I hardly suggest Implanon unless a client wants it... ? (Professional nurse H, DKKD)

'... I wouldn't go for it. I would stick to the known method - the pill or the injection. They've been around forever ... It has its sideeffects, but when you deal with it, it's sorted ... For instance, when they take the injection, they bleed and I give them Ovral. It settles as the body adjusts to the method ... I don't think it's [Implanon NXT] working, honestly, because of the removals we are doing and they [users] will tell you that they will never go for this method again ... ? (Professional nurse B, DKKD)

From the above, one can understand that nurses' negative experiences and attitudes towards the implant could make it difficult for them to exercise their responsibility as professionals to provide women with balanced information about the advantages and disadvantages of the method. Although nurses appear to take this responsibility seriously, overtly or in more subtle ways, it is possible that their biases and beliefs about the implant will influence the information they give during counselling, as well as discussions they have with people in the community more broadly. A study in the USA found that family planning service providers attached strong personal beliefs to certain contraceptive methods (including the implant) and refused to suggest these to certain clients, as they believed that those methods were not appropriate for them. ${ }^{[24]}$ Importantly, since the implant method requires users to return to clinics for discontinuation (unlike most other contraceptive methods), it could create an impression among providers that most users are unhappy with the method. Clearly, much work is needed to redress the perceptions and attitudes of family planning providers towards the implant, and to undo some of the biases that have developed around the method. The nurses suggested that awareness and additional campaigns are required among healthcare providers and women.

\section{'Men don't usually support women': Ensuring male involvement in family planning services}

This theme explores providers' perceptions of men's involvement in and influence over their partner's use of the implant, as illustrated in the following quotes:

'... No! There are no males that come here with the females, they all come alone. Some of them [women] often hide the implant from their partners ... ? (Professional nurse B, CoJ)

... I prefer women to talk to their partners before using the implant, because if it happens that a woman gets side-effects, at least a man is aware of what is going on ... ? (Professional nurse G, DKKD)

'... Men usually don't support women even when they come for oral pills or injectable, so it's even worse when they find out their partners want the implant ... ? (Professional nurse H, DKKD)

'... Men detest it [Implanon NXT], they don't like it at all because of the bleeding ... most people engage in relationships for sex more than love ... For example, a woman who is having sexual relationships came here crying that her partner ... they have three kids together ... left because of continuous excessive bleeding. He said to her that he would look for a woman who is not always bleeding because he wanted to have sex.' (Professional nurse E, CoJ) 'It is important for male partners [of Implanon NXT users] to support their female partners because once a woman starts experiencing side-effects she will be open with her partner and they can both come to the clinic to find a solution .... ? (Professional nurse A, DKKD)

It is evident that providers believed that men were often not supportive of their partners' use of the implant, leading to women attempting to conceal its use or discontinue the method. Other studies have similarly noted that men's knowledge and attitudes about contraceptive methods impact on women's preferences, ${ }^{[25-28]}$ and even that some men believe that they should take the final decision on contraception, while women take responsibility for usage. ${ }^{[29]}$

While men generally seem to regard family planning clinics as a woman's domain, ${ }^{[25,28,30,31]}$ the majority of nurses interviewed believe that involving men in family planning services would enlighten them and make them more supportive of their partner's contraceptive use. Men could thus play an important role in uptake and continuation of Implanon NXT, and in supporting women when they experience side-effects, e.g. irregular bleeding. As shown previously, couples who communicate about the use of family planning and family size are more likely to use a contraceptive method and achieve their reproductive objectives than those who do not. ${ }^{[25,31]}$ Clearly, there is a need for novel strategies to raise men's involvement in family planning services and foster a supportive attitude of men towards family planning. ${ }^{[2,32,33]}$

\section{Study limitations and strengths}

The small size restricted our ability to examine some aspects of our findings in detail, or to determine whether experiences of nurses were specific to some facilities or common to many. We included participants from seven clinics, which is a strength of the study, as it allowed us to draw on a range of experiences across sites. Moreover, this research is timely and important, given that the factors influencing the uptake and usage of Implanon NXT in SA have not 
been examined since its launch in 2014. This evidence comes at an important juncture for the service - i.e. the third stage of the World Health Organization framework on contraceptive introduction ${ }^{[34]}$ - where it is critical to have detailed research analysis, followed by the development of appropriate strategies to maintain services and redress problems that have emerged to date.

\section{Conclusion}

This article, focusing on providers' perspectives, adds to our understanding of current issues and challenges emanating from implant provision in SA, especially with regard to healthcare provider competence and attitudes towards the method. Overall, the findings of the study suggest that a concerted effort is needed to raise the competency of family planning providers, together with mass campaigns increasing the public's awareness of the benefits of the implant, as well as its side-effects and how these might be mitigated. Importantly, providers require guidance on the counselling and clinical management of bleeding patterns and other side-effects common to Implanon NXT. Improving providers' readiness to perform removal procedures, and the development of more structured removal services, is critical if quality, rights-based implant services are to be provided. To ensure the support of men, Implanon NXT awareness measures also need to target them; this possibly also applies to other contraceptive methods. In summary, the findings and recommendations of this study could inform a national effort to reinvigorate and improve implant services, which is urgently needed to secure the method's long-term viability in SA. Most especially, retraining and support of healthcare providers are required to address competency and confidence challenges and negative attitudes.

Acknowledgements. We thank the National Department of Health for allowing us access to the health facilities, the anonymous reviewers of this article, clinics that participated, and the nurses who gave their time to contribute to this study. We would also like to acknowledge the data collectors (Fortunate Gombela, Iris Sishi, Lindiwe Mbuyisa, Ntombenhle Twala, Siziwe Sidabuka and Tebogo Mokoena).

Author contributions. OAA was responsible for the qualitative component of the study, write-up, and was supported by CM, MP, DP, NN, MFC and SM. HR, the senior author, provided oversight and review.

Funding. Funding was received from the United Nations Population Fund (UNFPA), which also provided technical assistance.

Conflicts of interest. None.

1. United Nations Department of Economic and Social Affairs. Sustainable Development Goals: Sustainable Development Knowledge Platform, 2015. Geneva: UNDESA, 2015.

2. Family Planning 2020. What we do. 2016. http://www.familyplanning2020.org/microsite/about-us (accessed 15 May 2017).
3. Lince-Deroche N, Pleaner M, Morroni C, et al. Achieving universal access to sexual and reproductive health services: The potential and pitfalls for contraceptive services in South Africa. S Afr Health Review 2016;2016(1):95-108.

4. Chersich $\mathrm{M}$, Wabiri N, Risher K, et al. Contraception coverage and methods used among women in South Africa: A national household survey. S Afr Med J 2017;107(4):307-314. https://doi.org/10.7196/ South Africa: A national

5. Patel M. Contraception: Everyone’s responsibility. S Afr Med J 2014;104(9):644. https://doi.org/10.7196 SAMJ.8764

6. Department of Health. National Contraception Policy Guidelines. Pretoria: DoH, 2001.

6. Department of Health. National Contraception Policy Guidelin
7. Republic of South Africa. National Health Act No. 61 of 2003. 7. Republic of South Africa. National Health Act No. 61 of 2003 .
8. Department of Social Development. National Adolescent Sexual and Reproductive Health and Rights

Framework Strategy 2014 - 2019. Pretoria: DSD, 2015. Duvall S, Thurston S, Weinberger M, et al. Scaling up delivery of contraceptive implants in sub-Saharan Africa: Operational experiences of Marie Stopes International. Glob Health: Sci Pract 2014;2(1):72-92. https://doi.org/10.9745/GHSP-D-13-00116

10. Cleland JG, Ndugwa RP, Zulu EM. Family planning in sub-Saharan Africa: Progress or stagnation? Bull World Health Organ 2011;89(2):137-143. https://doi.org/10.2471/blt.10.077925

11. Department of Health, Statistics South Africa, South African Medical Research Council. South Africa Demographic and Health Survey 2016: Key Indicators. Pretoria: Stats SA, 2017.

12. Abraham $M, Z$ hao $Q$, Peipert JF. Young age, nulliparity, and continuation of long-acting reversible contraceptive methods. Obstet Gynecol 2015;126(4):823-829. https://doi.org/10.1097/AOG.0000000000001036

13. Teunissen AM, Grimm B, Roumen FJ. Continuation rates of the subdermal contraceptive Implanon and associated influencing factors. Eur J Contracept Reprod Health Care 2014;19(1):15-21. https://doi. org/10.3109/13625187.2013.862231

14. Diedrich JT, Klein DA, Peipert JF. Long-acting reversible contraception in adolescents: A systematic review and meta-analysis. Am J Obstet Gynecol 2017;216(4):el-e64. https://doi.org/10.1016/j. ajog.2016.12.024

15. Weisberg E, Bateson D, McGeechan K, et al. A three-year comparative study of continuation rates, bleeding patterns and satisfaction in Australian women using a subdermal contraceptive implant or progestogen releasing-intrauterine system. Eur I Contracept Reprod Health Care 2014:19(1):5-14. progestogen releasing-intrauterine system. Eu
https://doi.org/10.3109/13625187.2013.853034

16. Weisberg E, Fraser I. Australian women's experience with Implanon. Austr Fam Phys 2005;34(8):694.

17. Harvey C, Seib C, Lucke J. Continuation rates and reasons for removal among Implanon ${ }^{\circ}$ users accessing two family planning clinics in Queensland, Australia. Contraception 2009;80(6):527-532. https://doi. two family planning clinics in Queensla
org/10.1016/j.contraception.2009.05.132

18. Gold J, Burke E, Cissé B, et al. Increasing access to family planning choices through public-sector social franchising: The experience of Marie Stopes International in Mali. Glob Health: Sci Pract social franchising: The experience of Marie Stopes Internationa
2017;5(2):286-298. http://doi.org/10.9745/GHSP-D-17-00011

19. Denz; (2):286-298. https://doi.org/10.9745/GHSP-D-17-00011

19. Denzin NK, Lincoln YS. The Sage Handbook of Qualitative Research. UK: Sage, 2011. Adams B. Subdermal implants: A recent addition to the choice of South African contraceptives. Prof Nurs Today 2015;19(2):32-3

1. Blumenthal PD, Gemzell-Danielsson K, Marintcheva-Petrova M. Tolerability and clinical safety of Implanon. Eur I Contracept Reprod Health Care 2008;13(Suppl 1):29-36. https://doi. org $/ 10.1080 / 13625180801960012$

22. Mansour $D$, Korver T, Marintcheva-Petrova $M$, et al. The effects of Implanon ${ }^{\circ}$ on menstrual bleeding patterns. Eur J Contracept Reprod Health Care 2008;13(suppl 1):13-28. https://doi.org/10.1080/13625180801959931 23. Jacobstein R, Stanley H. Contraceptive implants: Providing better choice to meet growing family planning demand. Glob Health: Sci Pract 2013;1(1):11-17. https://doi.org/10.9745/GHSP-D-12-00003

24. Akers AY, Gold MA, Borrero S, et al. Providers' perspectives on challenges to contraceptive counseling in primary care settings. J Wom Health 2010;19(6):1163-1170. https://doi.org/10.1089/ jwh.2009.1735

5. Ijadunola MY, Abiona TC, Ijadunola KT, et al. Male involvement in family planning decision making in Ile-Ife, Osun State, Nigeria. Afr J Reprod Health 2010;14(4):43-50.

6. Mbizvo MT, Adamchak DJ. Family planning knowledge, attitudes, and practices of men in Zimbabwe. Stud Fam Plan 1991;22(1):31-38. https://doi.org/10.2307/1966517

27. Ezeh AC, Seroussi M, Raggers H. Men's fertility contraceptive use and reproductive preferences. DHS Comparative Studies 1996;8(18):45. https://www.popline.org/node/297753

28. Oyediran KA, Ishola GP, Feyisetan BJ. Factors affecting ever-married men's contraceptive knowledge and use in Nigeria. J Biosoc Sci 2002;34(4):497-510. https://doi.org/10.1017/S0021932002004972

29. Puri C, Balaiah D, Iyer K. Increased male responsibility and participation: A key to improving the reproductive health. ICMR Bull 1999:29(6):59.

30. Mason K, Lynam P. Not for women only: Child-spacing clubs for Malawian men. AVSC News 1992;30(4):4.

31. Khan M, Patel B. Male Involvement in Family Planning: A KABP Study of Agra District India. Final Report. New Delhi: Population Council, 1997.

32. Ogunjuyigbe PO. Spousal communication, changes in partner attitude and contraceptive use among the Ogunjuyigbe PO. Spousal communication, changes in pa
Yorubas of Southwest Nigeria. J Soc Sci 2002;6(1):59-64.

33. Lalla T. Male involvement in family planning: A review of the literature and selected program initiatives Lalla T. Male involvement in family planning: A review of the literature and selected program initiatives
in Africa 1996. https://pdfs.semanticscholar.org/15a6/5e5df695118e7961 5 c21012452df44bccbl.pdf in Africa 1996. https://pdis.
(accessed 11 September 2017)

34. Spicehandler J, Simmons R. Expanding Family Planning Options: Contraceptive Introduction

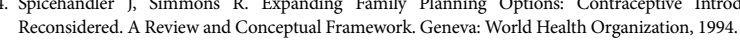

Accepted 23 August 2017. 